\title{
Multidrug-resistant genes of aminoglycoside- modifying enzymes and 16S rRNA methylases in Acinetobacter baumannii strains
}

\author{
J.-T. Wen, Y. Zhou, L. Yang and Y. Xu \\ Department of Clinical Laboratory, \\ The Second People's Hospital of Lianyungang City, Lianyungang, \\ Jiangsu Province, China \\ Corresponding author: Y. Zhou \\ E-mail: yanzhoucn@126.com
}

Genet. Mol. Res. 13 (2): 3842-3849 (2014)

Received July 30, 2013

Accepted December 16, 2013

Published May 16, 2014

DOI http://dx.doi.org/10.4238/2014.May.16.9

\begin{abstract}
We examined the distribution of genes of aminoglycosidemodifying enzymes and $16 \mathrm{~S}$ rRNA methylases in multidrug-resistant Acinetobacter baumannii to explore the association of these genes with drug resistance. Strains isolated from clinical specimens were screened using an automatic microbial identification system, and 9 aminoglycosidemodifying enzyme and 6 16S rRNA methylase genes were analyzed using polymerase chain reaction and verified by DNA sequencing. Next, sequence alignment was carried out using the Chromas software and a susceptibility test was performed using the Kirby-Bauer disk diffusion method. Genes encoding aminoglycoside-modifying enzymes were detected in all 20 strains of multidrug-resistant $A$. baumannii. The positive rates of $a a c\left(3^{\prime}\right)-I$, aac $\left(6^{\prime}\right)-I b$, ant $\left(3^{\prime \prime}\right)-I$, and $a p h\left(3^{\prime}\right)-I$ were 90.0, $90.0,85.0$, and $35.0 \%$, respectively. However, genes encoding $16 \mathrm{~S}$ rRNA methylases were not positively detected in the 20 strains of multidrugresistant $A$. baumannii. The resistance of multidrug-resistant $A$. baumannii
\end{abstract}


may be associated with aminoglycoside-modifying enzyme genes but not with 16S rRNA methylase genes.

Key words: Acinetobacter baumannii; 16S rRNA methylases; Aminoglycoside-modifying enzymes; Multidrug-resistant

\section{INTRODUCTION}

Acinetobacter baumannii is a parasite that is widely distributed in nature and in the human body. Because of extensive application of broad-spectrum antibiotics, an increasing number of multi-drug resistant strains of $A$. baumannii have appeared, which have become important pathogens of nosocomial infection (Fishbain and Peleg, 2010; Gordon and Wareham, 2010; Hou et al., 2012). These strains show strong resistance to the external environment and can acquire multidrug resistance quickly by carrying many movable genetic elements for multiple resistance genes (Golanbar et al., 2011; Taherikalani et al., 2011). The increasing occurrence of drug-resistant $A$. baumannii has caused concern in global medicine (Baumgart et al., 2010; Tasbakan et al., 2011).

$\beta$-Lactams drugs are bactericides used in the multiplication stage, whereas aminoglycoside are bactericides used during the rest period. It is commonly understood that these 2 drugs have a synergistic effect. Thus, a combination of aminoglycosides (such as Gentamicin) and $\beta$-lactams (such as Imipenem) has been commonly used for treating $A$. baumannii infections. However, due to its production of OXA-23-type $\beta$-lactamase, imipenem-resistant $A$. baumannii has become a worldwide problem (Mugnier et al., 2010; Poirel et al., 2010; Kim et al., 2012). Along with the increasing rate of drug resistance to $\beta$-lactams, drug resistance to aminoglycoside is also increasing, and clinically isolated aminoglycoside-resistant strains have become common (Brigante et al., 2012). There are 2 main reasons for Gram-negative bacilli resistance to aminoglycosides. The first is that aminoglycosides entering bacteria are modified by aminoglycoside-modifying enzymes and become non-functional. The second is that methylation of target sites is induced by $16 \mathrm{~S}$ rRNA methylases, leading to decreased affinity of $16 \mathrm{~S}$ rRNA for aminoglycosides (Galimand et al., 2000; Davis et al., 2010; Zhou et al., 2010).

Regional differences in the drug resistance of bacteria have been observed; the resistance gene carried by some strains also varies from location to location. Genes encoding aminoglycoside-modifying enzymes and 16S rRNA methylase in multidrug-resistant $\mathrm{A}$. baumannii should be examined to investigate their relationship to the development of drug resistance. In this study, 9 aminoglycoside-modifying enzyme genes and 6 16S rRNA methylase genes were investigated in 20 strains of multidrug-resistant $A$. baumannii isolated from the Lianyungang region in China. The objective of this study was to increase understanding of the prevalence of multidrug-resistant $A$. baumannii in this region, provide guidance for research and development of new drugs, and facilitate clinical anti-infection treatment and reasonable use of antimicrobial agents for early rehabilitation of patients.

\section{MATERIAL AND METHODS}

\section{Collection of the strains}

Twenty strains of multidrug-resistant $A$. baumannii were isolated from sputum 
specimens of patients hospitalized in the Second People's Hospital, Lianyungang, Jiangsu, China, from January 2011 to December 2011. This study was conducted in accordance with the Declaration of Helsinki and with approval from the Ethics Committee of the Second People's Hospital of Lianyungang City. Written informed consent was obtained from all participants.

\section{Strain identification}

Because biochemical identification methods cannot distinguish between $A$. baumannii and Acinetobacter calcoaceticus, strain identification was conducted using an automatic microbial identification system (Siemens Healthcare Diagnostics; Malvern, PA, USA) for initial screening and amplification of the $\operatorname{gyr} A$ and $\operatorname{parC}$ genes using a polymerase chain reaction (PCR) technique in this study. After DNA sequencing of the PCR products and matching their sequences against the National Center for Biotechnology Information database (www.ncbi.nlm.nih.gov), the strains confirmed as A. baumannii were selected for further analysis.

\section{Susceptibility test}

The NC31 Gram-negative bacteria identification and susceptibility board (Siemens) was used to preliminarily assess the minimum inhibitory concentration (MIC) susceptibility results of the strains against the 14 drugs recommended by the Clinical and Laboratory Standards Institute (CLSI), including piperacillin, cefotaxime, ceftazidime, ceftriaxone, cefepime, imipenem, ampicillin/sulbactam, ticarcillin/clavulanic acid, gentamicin, tobramycin, amikacin, ciprofloxacin, levofloxacin, and compounded sulfamethoxazole. Subsequently, the Kirby-Bauer disk diffusion method (Oxoid Microbiology Products; Basingstoke, UK) was used to verify multidrug resistance. Antimicrobial susceptibility determination was based on the criteria outlined in the 2011 edition of the CLSI. The Mueller-Hinton (M-H) medium was obtained from Oxoid Microbiology Products.

\section{DNA extraction}

One single colony of each strain was picked from the purified culture and transferred into a $0.5-\mathrm{mL}$ EP tube containing $400 \mu \mathrm{L} 200 \mathrm{ng} / \mathrm{mL}$ freshly prepared proteinase K. After incubation at $56^{\circ} \mathrm{C}$ for $2 \mathrm{~h}$ to destroy the bacterial membrane and release the DNA, the tube was then incubated at $95^{\circ} \mathrm{C}$ for 10 min to inactivate proteinase $\mathrm{K}$. Before PCR, all DNA samples were stored at $-20^{\circ} \mathrm{C}$.

\section{Gene detection}

Nine aminoglycoside-modifying enzyme genes and 6 16S rRNA methylase genes were detected using PCR according to manufacturer instructions of the PCR kit (Wuxi Institute of Cloning and Genetic Technology; Jiangsu, China). All gene-specific primers were designed and provided by Zuhuang Mi, Department of Bioinformatics, Wuxi Institute of Cloning and Genetic Technology, Jiangsu, China (Table 1). 


\begin{tabular}{|c|c|c|c|}
\hline Class & Gene & Primer & $\begin{array}{r}\text { Product } \\
\text { size (bp) }\end{array}$ \\
\hline \multirow[t]{9}{*}{ Aminoglycoside-modifying enzymes } & $\operatorname{aac}(3)-I$ & $\begin{array}{l}\text { P1: ACCTACTCCCAACATCAGCC; } \\
\text { P2: ATATAGATCTCACTACGCGC }\end{array}$ & 169 \\
\hline & $\operatorname{aac}(3)-I I$ & $\begin{array}{l}\text { P1: ACTGTGATGGGATACGCGTC; } \\
\text { P2: CTCCGTCAGCGTTTCAGCTA }\end{array}$ & 237 \\
\hline & $a a c\left(6^{\prime}\right)-I a d$ & $\begin{array}{l}\text { P1: ATGATTAGAAAAGCAACTGTCCAAG; } \\
\text { P2: TTAAAGTTGCTTTGTAAAACAAATC }\end{array}$ & 435 \\
\hline & $a a c\left(6^{\prime}\right)-I b$ & $\begin{array}{l}\text { P1: ATGACTGAGCATGACCTTGC; } \\
\text { P2: TTAGGCATCACTGCGTGTTC }\end{array}$ & 519 \\
\hline & $\operatorname{aac}\left(6^{\prime}\right)-I I$ & $\begin{array}{l}\text { P1: TTCATGTCCGCGAGCACCCC; } \\
\text { P2: GACTCTTCCGCCATCGCTCT }\end{array}$ & 178 \\
\hline & $\operatorname{ant}\left(3^{\prime \prime}\right)-I$ & $\begin{array}{l}\text { P1: TGATTTGCTGGTTACGGTGAC; } \\
\text { P2: CGCTATGTTCTCTTGCTTTTG }\end{array}$ & 284 \\
\hline & $\operatorname{ant}\left(2^{\prime \prime}\right)-I$ & $\begin{array}{l}\text { P1: GAGCGAAATCTGCCGCTCTGG; } \\
\text { P2: CTGTTACAACGGACTGGCCGC }\end{array}$ & 320 \\
\hline & $\operatorname{ant}\left(4^{\prime}\right)-I$ & $\begin{array}{l}\text { P1: CGTGGAGCGATATCGATTTCG; } \\
\text { P2: TCTGGTTCGGCGGCCGGATGC }\end{array}$ & 266 \\
\hline & $\operatorname{aph}\left(3^{\prime}\right)-I$ & $\begin{array}{l}\text { P1: ATGTGCCATATTCAACGGGAAACG; } \\
\text { P2: TCAGAAAAACTCATCGAGCATCAA }\end{array}$ & 816 \\
\hline \multirow[t]{6}{*}{ 16S rRNA methylases } & $r m t A$ & $\begin{array}{l}\text { P1: CCTAGCGTCCATCCTTTCCTC; } \\
\text { P2: AGCGATATCCAACACACGATGG }\end{array}$ & 315 \\
\hline & $r m t B$ & $\begin{array}{l}\text { P1: TGCGGCGCATCCTGACTGAGGA; } \\
\text { P2: GGGAAAGCTGACAGCCATGCGC }\end{array}$ & 542 \\
\hline & $\mathrm{rmtC}$ & $\begin{array}{l}\text { P1: ATGAAAACCAACGATAATTATC; } \\
\text { P2: TTACAATCTCGATACGATAAAATAC }\end{array}$ & 846 \\
\hline & $r m t D$ & $\begin{array}{l}\text { P1: ATGAGCGAACTGAAGGAAAAACTGCT; } \\
\text { P2: TCATTTTCGTTTCAGCACGTAAAACAG }\end{array}$ & 744 \\
\hline & $\operatorname{arm} A$ & $\begin{array}{l}\text { P1: ATGGATAAGAATGATGTTGTTAAG; } \\
\text { P2: TTATTTCTGAAATCCACTAGTAATTA }\end{array}$ & 774 \\
\hline & $n p m A$ & $\begin{array}{l}\text { P1: TTGGGTACTGGAGACGGTAG; } \\
\text { P2: CAGCTTTGTATTGTTCGCTC }\end{array}$ & 421 \\
\hline
\end{tabular}

\section{DNA sequencing}

Positive PCR products were sent to Shanghai Boshang Biological Technology, Ltd., Co. for DNA sequencing. An Applied Biosystems 3730xl DNA Sequencer (Applied Biosystems; Foster City, CA, USA) was used.

\section{Sequence alignment} search tools.

DNA sequences were read using the Chromas software and aligned using BLAST

\section{RESULTS}

\section{Drug resistance of $A$. baumannii}

The susceptibility of the 20 strains of $A$. baumannii against the 14 antibiotics was similar according to the results of two different susceptibility test methods (Table 2). All strains were fully resistant to piperacillin, ceftazidime, ceftriaxone, cefepime, and imipenem. The resistance rate against aminoglycosides, fluoroquinolones, and trimethoprim-sulfamethoxazole was more than $90.0 \%$. For instance, the resistance of all 20 strains of A. baumannii against 
gentamicin, tobramycin, amikacin, and other aminoglycoside drugs was more than $90 \%$. All 20 strains of A. baumannii showed resistance to 3 or more different classes of antibiotics simultaneously; thus, they conformed to the criteria of multi-drug resistance.

\begin{tabular}{|c|c|c|c|}
\hline Drugs & Resistant (R\%) & Intermediate (I\%) & Sensitive (S\%) \\
\hline Piperacillin & $20(100.0$ & $0(0)$ & $0(0)$ \\
\hline Cefotaxime & $18(90.0)$ & $2(10.0)$ & $0(0)$ \\
\hline Ceftazidime & $20(100.0)$ & $0(0)$ & $0(0)$ \\
\hline Ceftriaxone & $20(100.0)$ & $0(0)$ & $0(0)$ \\
\hline Cefepime & $20(100.0)$ & $0(0)$ & $0(0)$ \\
\hline Imipenem & $20(100.0)$ & $0(0)$ & $0(0)$ \\
\hline Ampicillin/Sulbactam & $19(95.0)$ & $1(5.0)$ & $0(0)$ \\
\hline Ticarcillin/Clavulanic acid & $19(95.0)$ & $1(5.0)$ & $0(0)$ \\
\hline Gentamicin & $18(90.0)$ & $2(10.0)$ & $0(0)$ \\
\hline Tobramycin & $18(90.0)$ & $2(10.0)$ & $0(0)$ \\
\hline Amikacin & $18(90.0)$ & $2(10.0)$ & $0(0)$ \\
\hline Ciprofloxacin & $18(90.0)$ & $2(10.0)$ & $0(0)$ \\
\hline Levofloxacin & $18(90.0)$ & $2(10.0)$ & $0(0)$ \\
\hline Trimethoprim+Sulfamethoxazole & $18(90.0)$ & $2(10.0)$ & $0(0)$ \\
\hline
\end{tabular}

\section{Aminoglycosides-modifying enzyme genes in the 20 strains of $A$. baumannii}

All 9 aminoglycoside-modifying enzyme genes were positively detected, among which the positive rates of aac( $\left.3^{\prime}\right)-I$, aac (6')-Ib, ant( $\left.3^{\prime \prime}\right)-I$, and $\operatorname{aph}\left(3^{\prime}\right)-I$ were $90.0 \%(18 / 20)$, $90.0 \%(18 / 20), 85.0 \%(17 / 20)$, and $35.0 \%$ (7/20), respectively. One strain contained aac (3')-I and $a a c\left(6^{\prime}\right)-I b, 2$ strains contained only $a a c\left(3^{\prime}\right)-I, 2$ strains contained $a a c\left(6^{\prime}\right)-I b$, ant (3")-I, and $a p h\left(3^{\prime}\right)-I, 5$ strains contained $a a c\left(3^{\prime}\right)-I, a a c\left(6^{\prime}\right)-I b$, ant (3') $-I$, and $a p h\left(3^{\prime}\right)-I$, and 10 strains contained $a a c\left(3^{\prime}\right)-I, a a c\left(6^{\prime}\right)-I b$, and ant (3")-I (Table 3). DNA sequencing results of the PCR products were confirmed using the BLASTn tool (www.ncbi.nlm.nih.gov/BLASTn) (Figure 1).

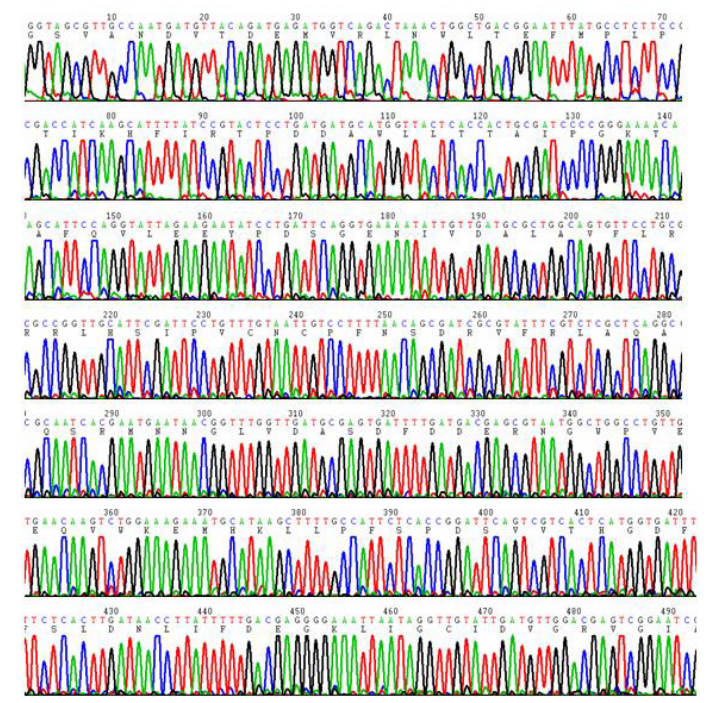

Figure 1. DNA sequence of the PCR product of the aph(3')-I gene in the \#8 strain, confirmed by DNA alignment using the BLASTn tool (www.ncbi.nlm.nih.gov/BLASTn). 
Table 3. Positive patterns of the aminoglycoside-modifying enzyme genes in Acinetobacter baumannii.

\begin{tabular}{lc}
\hline Gene-positive patterns & Positive number (\%) \\
\hline$a a c\left(3^{\prime}\right)-I+a a c\left(6^{\prime}\right)-I b+\operatorname{ant}\left(3^{\prime \prime}\right)-I$ & $10(50.0 \%)$ \\
$\operatorname{aac}\left(3^{\prime}\right)-I+\operatorname{aac}\left(6^{\prime}\right)-I b+\operatorname{ant}\left(3^{\prime \prime}\right)-I+\operatorname{aph}\left(3^{\prime}\right)-I$ & $5(25.0 \%)$ \\
$\operatorname{aac}\left(6^{\prime}\right)-I b+\operatorname{ant}\left(3^{\prime \prime}\right)-I+\operatorname{aph}\left(3^{\prime}\right)-I$ & $2(10.0 \%)$ \\
$\operatorname{aac}\left(3^{\prime}\right)-I$ & $2(10.0 \%)$ \\
$\operatorname{aac}\left(3^{\prime}\right)-\operatorname{aac}\left(6^{\prime}\right)-I b$ & $1(5.0 \%)$ \\
\hline
\end{tabular}

\section{S rRNA methylase genes in the 20 strains of $A$. baumannii}

None of the $616 \mathrm{~S}$ rRNA methylase genes was detected positively in the 20 strains of A. baumannii.

\section{DISCUSSION}

Since aminoglycosides (Streptomycin) were first identified 70 years ago, aminoglycoside drugs have been commonly used for treatment. Most aminoglycosides are natural antibacterial substances produced by microorganisms, but a few, such as amikacin and isepamicin, are semi-synthetic derivatives of natural compounds. Aminoglycosides are broad-spectrum bactericidal agents. They have killing effects on most pathogens and opportunistic pathogens isolated clinically, except for anaerobes. This may be because aminoglycosides carry protons, which can easily interact with the negative charge on a bacterial cell surface, facilitating binding to nucleic acids. When increasing numbers of aminoglycosides bind to the A site of the bacterial ribosome, which is not only the aminoacyl-tRNA binding site, but also the codonanticodon recognition region, mistranslation of mRNA into an amino acid sequence can occur, resulting in the production of abnormal proteins, and bacterial cell death.

The drug resistance of $A$. baumannii has become increasingly important and causes great difficulties in the clinical treatment of bacterial infections (Shahcheraghi et al., 2011; Doi, 2012; Wang et al., 2012). The 20 strains of A. baumannii analyzed in this study were isolated from sputum specimens from in-patients. They were all insensitive to the commonly used cephalosporins, including imipenem, and the cephalosporin complex preparations. Their resistance to aminoglycosides, fluoroquinolones, and trimethoprim-sulfamethoxazole reached greater than $90 \%$, among which resistance against gentamicin, tobramycin, amikacin, and other aminoglycoside-based drugs was more than $90 \%$. Thus, the resistance of the 20 strains of $A$. baumannii isolated in this study is very alarming. Garnacho-Montero and Amaya-Villar (2010) found that polymyxin has a clear curative effect on multidrug-resistant A. baumannii. However, a study by Moffatt et al. (2010) showed that $A$. baumannii has heterogeneous resistance to polymyxin, and that the heterogeneous resistance strain can partially recover its sensitivity to other antibacterial drugs. Therefore, polymyxin combined with $\beta$-lactam antibiotics or tigecycline is a potential alternative for inhibiting $A$. baumannii, but this requires confirmation through large-scale clinical studies.

Aminoglycoside-modifying enzymes can be divided into 3 categories according to their functions: 1) acetyltransferase (AACs), whose related genes include aac(3)-I, aac(3)-II, and $a a c\left(6^{\prime}\right)-I b$, among others, and can cause acetylation of free hydroxyl groups; 2) phosphotransferase (APH), including aph(3')-I, leads to phosphorylation of free hydroxyl groups; 
3) nucleotide transferase (ANT), also known as adenosine transferase (AAD), includes $\operatorname{ant}\left(3^{\prime \prime}\right)-I$ and ant(2")- $I$, which can lead to nucleosidation of free hydroxyl groups. More than 30 aminoglycoside-modifying enzyme genes and $716 \mathrm{~S}$ rRNA methylase genes have been identified to date. In Europe, the most commonly observed aminoglycoside-modifying enzyme genes include $a a c(3)-I, a a c(3)-I I$, aac(6')-Ib, aph(3')-I, and ant(3")-I (Nemec et al., 2004). In this study, we detected 9 aminoglycoside-modifying enzyme genes from all 20 strains of $A$. baumannii. We found that all of the 20 strains of $A$. baumannii carried at least one type of aminoglycoside-modifying enzyme gene, among which both $a a c\left(3^{\prime}\right)-I$ and $a a c\left(6^{\prime}\right)-I b$ showed a positive rate of $90 \%(18 / 20)$, ant (3")-I showed a positive rate of $85 \%(17 / 20)$, and $\operatorname{aph}\left(3^{\prime}\right)-I$ showed a positive rate of $35 \%(7 / 20)$. These results are consistent with those of Nemec et al. (2004). Based on the positive patterns of the 20 strains of $A$. baumannii shown in Table 3, most $A$. baumannii possess $\geq 2$ aminoglycoside-modifying enzyme genes, except for the 2 strains possessing only one gene, aac (3')-I. Seven $16 \mathrm{~S}$ rRNA methylase genes have been previously identified, including $a r m A$, rmtA, $r m t B, r m t C, r m t D, r m t E$, and $n p m A$ (Davis et al., 2010; Zhou et al., 2010). The $r m t E$ gene was recently isolated from Escherichia coli from bovine (Davis et al., 2010). However, in the present study, the $616 \mathrm{~S}$ rRNA methylase genes tested were undetected in the 20 strains of $A$. baumannii. This is different from the results of previous studies (Davis et al., 2010; Zhou et al., 2010), which may be related to regional differences.

A cluster analysis conducted by Chinese researchers showed that aminoglycosidemodifying enzyme genes and 16S rRNA methylase genes are often associated with genetic markers of moveable genetic elements (Kansakar et al., 2011), i.e., these genes are removable rear-mediated genetic elements (Wu et al., 2009; Asadollahi et al., 2011). This acquired resistance mechanism facilitates horizontal spread. Genomic studies have revealed that multidrugresistant $A$. baumannii is rich in the efflux pump gene (Rajamohan et al., 2010; Zhou et al., 2011), and high expression of this gene plays an important role in the multidrug resistance of A. baumannii (Coyne et al., 2011). In future studies, mobile genetic elements and the efflux pump will be further investigated to determine their correlation with multidrug resistance.

In conclusion, the multidrug resistance of $A$. baumannii isolated from in-patients of our hospital was related to aminoglycoside-modifying enzyme genes but not to $16 \mathrm{~S}$ rRNA methylase genes.

\section{REFERENCES}

Asadollahi K, Taherikalani M, Maleki A, Alizadeh E, et al. (2011). Diversity of aminoglycoside modifying enzyme genes among multidrug resistant Acinetobacter baumannii genotypes isolated from nosocomial infections in Tehran hospitals and their association with class 1 integrons. Acta Microbiol. Immunol. Hung. 58: 359-370.

Baumgart AM, Molinari MA and Silveira AC (2010). Prevalence of carbapenem resistant Pseudomonas aeruginosa and Acinetobacter baumannii in high complexity hospital. Braz. J. Infect. Dis. 14: 433-436.

Brigante G, Migliavacca R, Bramati S, Motta E, et al. (2012). Emergence and spread of a multidrug-resistant Acinetobacter baumannii clone producing both the carbapenemase OXA-23 and the 16S rRNA methylase ArmA. J. Med. Microbiol. 61: 653-661.

Coyne S, Courvalin P and Perichon B (2011). Efflux-mediated antibiotic resistance in Acinetobacter spp. Antimicrob. Agents Chemother. 55: 947-953.

Davis MA, Baker KN, Orfe LH, Shah DH, et al. (2010). Discovery of a gene conferring multiple-aminoglycoside resistance in Escherichia coli. Antimicrob. Agents Chemother. 54: 2666-2669.

Doi Y (2012). Antimicrobial resistance testing in clinical practice. Nihon Rinsho 70: 272-275.

Fishbain J and Peleg AY (2010). Treatment of Acinetobacter infections. Clin. Infect. Dis. 51: 79-84.

Galimand M, Gerbaud G and Courvalin P (2000). Spectinomycin resistance in Neisseria spp. due to mutations in 16S 
rRNA. Antimicrob. Agents Chemother. 44: 1365-1366.

Garnacho-Montero J and Amaya-Villar R (2010). Multiresistant Acinetobacter baumannii infections: epidemiology and management. Curr. Opin. Infect. Dis. 23: 332-339.

Golanbar GD, Lam CK, Chu YM, Cueva C, et al. (2011). Phenotypic and molecular characterization of Acinetobacter clinical isolates obtained from inmates of California correctional facilities. J. Clin. Microbiol. 49: 2121-2131.

Gordon NC and Wareham DW (2010). Multidrug-resistant Acinetobacter baumannii: mechanisms of virulence and resistance. Int. J. Antimicrob. Agents 35: 219-226.

Hou PF, Chen XY, Yan GF, Wang YP, et al. (2012). Study of the correlation of imipenem resistance with efflux pumps AdeABC, AdeIJK, AdeDE and AbeM in clinical isolates of Acinetobacter baumannii. Chemotherapy 58: 152-158.

Kansakar P, Dorji D, Chongtrakool P, Mingmongkolchai S, et al. (2011). Local dissemination of multidrug-resistant Acinetobacter baumannii clones in a Thai hospital. Microb. Drug Resist. 17: 109-119.

Kim YJ, Kim SI, Kim YR, Hong KW, et al. (2012). Carbapenem-resistant Acinetobacter baumannii: diversity of resistant mechanisms and risk factors for infection. Epidemiol. Infect. 140: 137-145.

Moffatt JH, Harper M, Harrison P, Hale JD, et al. (2010). Colistin resistance in Acinetobacter baumannii is mediated by complete loss of lipopolysaccharide production. Antimicrob. Agents Chemother. 54: 4971-4977.

Mugnier PD, Poirel L, Naas T and Nordmann P (2010). Worldwide dissemination of the blaOXA-23 carbapenemase gene of Acinetobacter baumannii. Emerg. Infect. Dis. 16: 35-40.

Nemec A, Dolzani L, Brisse S, van den Broek P, et al. (2004). Diversity of aminoglycoside-resistance genes and their association with class 1 integrons among strains of pan-European Acinetobacter baumannii clones. J. Med. Microbiol. 53: $1233-1240$.

Poirel L, Naas T and Nordmann P (2010). Diversity, epidemiology, and genetics of class D beta-lactamases. Antimicrob. Agents Chemother. 54: 24-38.

Rajamohan G, Srinivasan VB and Gebreyes WA (2010). Novel role of Acinetobacter baumannii RND efflux transporters in mediating decreased susceptibility to biocides. J. Antimicrob. Chemother. 65: 228-232.

Shahcheraghi F, Abbasalipour M, Feizabadi M, Ebrahimipour G, et al. (2011). Isolation and genetic characterization of metallo- $\beta$-lactamase and carbapenamase producing strains of Acinetobacter baumannii from patients at Tehran hospitals. Iran J. Microbiol. 3: 68-74.

Taherikalani M, Maleki A, Sadeghifard N, Mohammadzadeh D, et al. (2011). Dissemination of class 1, 2 and 3 integrons among different multidrug resistant isolates of Acinetobacter baumannii in Tehran hospitals, Iran. Pol. J. Microbiol. 60: $169-174$.

Tasbakan MS, Pullukcu H, Sipahi OR, Tasbakan MI, et al. (2011). Is tigecyclin a good choice in the treatment of multidrugresistant Acinetobacter baumannii pneumonia? J. Chemother. 23: 345-349.

Wang DH, Chen M, Jiang ZQ, Wang P, et al. (2012). Investigation on epidemiology of carbapenem-resistant Acinetobacter baumannii and carbapenemases. Chin. J. Mod. Appl. Pharm. 29: 400-404.

Wu Q, Zhang Y, Han L, Sun J, et al. (2009). Plasmid-mediated 16S rRNA methylases in aminoglycoside-resistant Enterobacteriaceae isolates in Shanghai, China. Antimicrob. Agents Chemother. 53: 271-272.

Zhou H, Zhang T, Yu D, Pi B, et al. (2011). Genomic analysis of the multidrug-resistant Acinetobacter baumannii strain MDR-ZJ06 widely spread in China. Antimicrob. Agents Chemother. 55: 4506-4512.

Zhou Y, Yu H, Guo Q, Xu X, et al. (2010). Distribution of 16S rRNA methylases among different species of Gramnegative bacilli with high-level resistance to aminoglycosides. Eur. J. Clin. Microbiol. Infect. Dis. 29: 1349-1353. 